\title{
Alpha-N-acetylgalactosaminidase deficiency type 2
}

INSERM

\section{Source}

INSERM. (1999). Orphanet: an online rare disease and orphan drug data base. Alpha-Nacetylgalactosaminidase deficiency type 2. ORPHA:79280

Alpha-N-acetylgalactosaminidase (NAGA) deficiency type 2 is a very rare mild adult type of NAGA deficiency (see this term) with the features of angiokeratoma corporis diffusum (see this term) and mild sensory neuropathy. 